M. G. Wallis • M. E. Smith · C. M. Kolka • L. Zhang •

S. M. Richards $\cdot$ S. Rattigan $\cdot$ M. G. Clark

\title{
Acute glucosamine-induced insulin resistance in muscle in vivo is associated with impaired capillary recruitment
}

Received: 19 January 2005 / Accepted: 18 April 2005 / Published online: 30 July 2005

C) Springer-Verlag 2005

\begin{abstract}
Aims/hypothesis: Glucose toxicity and glucosamine-induced insulin resistance have been attributed to products of glucosamine metabolism. In addition, endothelial cell nitric oxide synthase is inhibited by glucosamine. Since insulin has endothelial nitric-oxide-dependent vasodilatory effects in muscle, we hypothesise that glucosamine-induced insulin resistance in muscle in vivo is associated with impaired vascular responses including capillary recruitment. Materials and methods: Glucosamine $\left(6.48 \mathrm{mg} \mathrm{kg}^{-1} \mathrm{~min}^{-1}\right.$ for $3 \mathrm{~h})$ was infused with or without insulin $\left(10 \mathrm{mU} \mathrm{kg}^{-1}\right.$ $\min ^{-1}$ ) into anaesthetised rats under euglycaemic conditions. Results: Glucosamine infusion alone increased blood glucosamine $(1.9 \pm 0.1 \mathrm{mmol} / \mathrm{l})$ and glucose $(5.4 \pm 0.2$ to $7.7 \pm$ $0.3 \mathrm{mmol} / \mathrm{l})(p<0.05)$ but not insulin. Glucosamine induced both hepatic and muscle insulin resistance as evident from measures of glucose appearance and disposal as well as hindleg glucose uptake, which was inhibited by approx. 50\% $(p<0.05)$. Insulin-mediated increases in femoral arterial blood flow and capillary recruitment were completely blocked by glucosamine. Conclusion/interpretation: Glucosamine mediates a major impairment of insulin action in muscle vasculature associated with the insulin resistance of muscle. Further studies will be required to assess whether the impaired capillary recruitment contributes to insulin resistance.
\end{abstract}

Keywords Capillary recruitment · Glucosamine · Insulin resistance $\cdot$ Muscle $\cdot$ Vascular effects

\footnotetext{
Abbreviations BP: blood pressure - 2DG: 2-deoxyglucose - eNOS: endothelial nitric oxide synthase FBF: femoral arterial blood flow - GFAT: glutamine fructose-6-phosphate amidotransferase - GIR: whole body glucose infusion rate $\cdot$ GlcN: $N$-glucosamine $\cdot \mathrm{HGU}$ : hind leg glucose uptake $\cdot 1-\mathrm{MX}$ : 1-methylxanthine $\cdot$ NO: nitric

M. G. Wallis · M. E. Smith · C. M. Kolka · L. Zhang ·

S. M. Richards - S. Rattigan · M. G. Clark $(\bowtie)$

Biochemistry, School of Medicine, University of Tasmania,

Private Bag 58 Hobart, Tasmania, 7001, Australia

e-mail: Michael.Clark@utas.edu.au

Tel.: +61-3-62262672

Fax: $+61-3-62262703$
}

oxide $\cdot$ NOS: nitric oxide synthase $\cdot \mathrm{R}_{\mathrm{a}}$ : hepatic glucose output $\cdot \mathrm{R}_{\mathrm{d}}$ : glucose disposal $\cdot \mathrm{R}_{\mathrm{g}}^{\prime}$ : $2 \mathrm{DG}$ uptake $\cdot$ VENIRKO: vascular endothelial insulin receptor knockout · VR: vascular resistance · VSMC: vascular smooth muscle cells

\section{Introduction}

Chronic hyperglycemia has been shown to induce insulin resistance, a phenomenon known as glucose toxicity [1]. This was demonstrated to be dependent on the presence of glucose, insulin and glutamine and to involve the hexosamine biosynthesis pathway [2-4]. Further studies revealed that insulin resistance could also be induced by glucosamine [4], which increases flux through the hexosamine biosynthesis pathway by bypassing the rate-limiting step catalysed by glutamine fructose-6-phosphate amidotransferase (GFAT). Overexpression of this enzyme in skeletal muscle and adipose tissue of transgenic mice has also been found to cause insulin resistance [5].

Whereas the earlier studies were carried out in adipocytes [2-4], glucosamine also induces insulin resistance in skeletal muscle and liver in vivo [6-9]. The rate of glycogen synthesis is reduced $[6,8]$ and glycolysis is either reduced $[6,7]$ or not affected [8]. Considering that glucosamine also induces insulin resistance in incubated muscles $[10,11]$, there is a cellular component to insulin resistance. However, it is also possible that there is a haemodynamic element with resultant impairment of both insulin-mediated limb blood flow and capillary recruitment. Inhibition of insulin's haemodynamic action has been shown to be associated with decreased insulin-mediated glucose uptake [12-14].

When infused locally [15], inhibitors of nitric oxide synthase (NOS) block insulin-mediated increases in blood flow, and also block insulin-mediated capillary recruitment when infused systemically [16]. For capillary recruitment, the higher sensitivity to insulin [17] and the fact that time course studies show capillary recruitment to be the earliest change caused by insulin in vivo [18] suggest that endothelial cells, in particular endothelial nitric oxide synthase 
(eNOS), are the source of nitric oxide (NO). Glucosamine inhibits eNOS [19] and the infusion of glucosamine in anaesthetised rats reduced limb blood flow during an insulin clamp where flow was assessed by radioactive microspheres [20], a measure of total flow to specific muscles.

Therefore, the aim of this study was to investigate whether glucosamine-induced insulin resistance in muscle in vivo also involves impairment of the haemodynamic actions of insulin, particularly capillary recruitment.

\section{Materials and methods}

Animals All procedures adopted and experiments undertaken were approved by the University of Tasmania Animal Ethics Committee. Male hooded Wistar rats (University of Tasmania Animal House, Hobart, TAS, Australia) weighing $245 \pm 3 \mathrm{~g}$ were raised on a commercial diet (Pivot, Launceston, TAS, Australia) containing $21.4 \%$ protein, $4.6 \%$ lipid, $68 \%$ carbohydrate and $6 \%$ crude fibre with added vitamins and minerals together with free access to water. Until the day of surgery, rats were housed at a constant temperature of $21 \pm 1^{\circ} \mathrm{C}$ with a $12 \mathrm{~h} / 12 \mathrm{~h}$ lightdark cycle. Food and water were freely available until animals were anaesthetised.

In vivo experiments These were carried out in anaesthetised rats as described previously [21]. Anaesthesia was necessary to prevent movement effects on capillary recruitment and was introduced using Nembutal $50 \mathrm{mg} / \mathrm{kg}$ body weight and maintained for the duration of the experiment using a continual infusion of $0.6 \mathrm{mg} \mathrm{min}^{-1} \mathrm{~kg}^{-1}$ via the left jugular cannula. In brief, polyethylene cannulas (PE-50, Intramedic, Beckton Dickinson, Parsippany, NJ, USA) were surgically implanted into the carotid artery for arterial sampling and continuous measurement of blood pressure (pressure transducer Transpac IV, Abbott Critical Care Systems, Morgan Hill, CA, USA), and into both jugular veins for continuous administration of anaesthetic and other intravenous infusions. A tracheotomy tube was inserted and the animal was allowed to breathe room air spontaneously throughout the course of the experiment. Small incisions $(1.5 \mathrm{~cm})$ were made in the skin overlaying the femoral vessels of both legs, the femoral artery was separated from the femoral vein and saphenous nerve, and an ultrasonic flow probe (VB series $0.5 \mathrm{~mm}$; Transonic Systems, Ithaca, NY, USA) was positioned around the femoral artery of one leg just distal to the rectus abdominis muscle prior to the point where the epigastric artery leaves the femoral artery. After placement of all cannulae, of the flow probe, and following $1 \mathrm{~h}$ of equilibration, rats were infused for $3 \mathrm{~h}$ with either glucosamine $\left(6.48 \mathrm{mg} \mathrm{kg}^{-1} \mathrm{~min}^{-1}\right.$, Sigma Chemical, St Louis, MO, USA), insulin (10 mU kg-1 $\min ^{-1}$, Humulin R, Eli Lilly, Indianapolis, IN, USA) or both, as shown by Protocols 1, 2 and 3, respectively in Fig. 1. In rats receiving insulin, blood glucose was maintained at the initial level by the infusion of $30 \%$ glucose. At the end of the experiment blood was sampled from the femoral vein and carotid artery. Hind leg glucose uptake was calculated
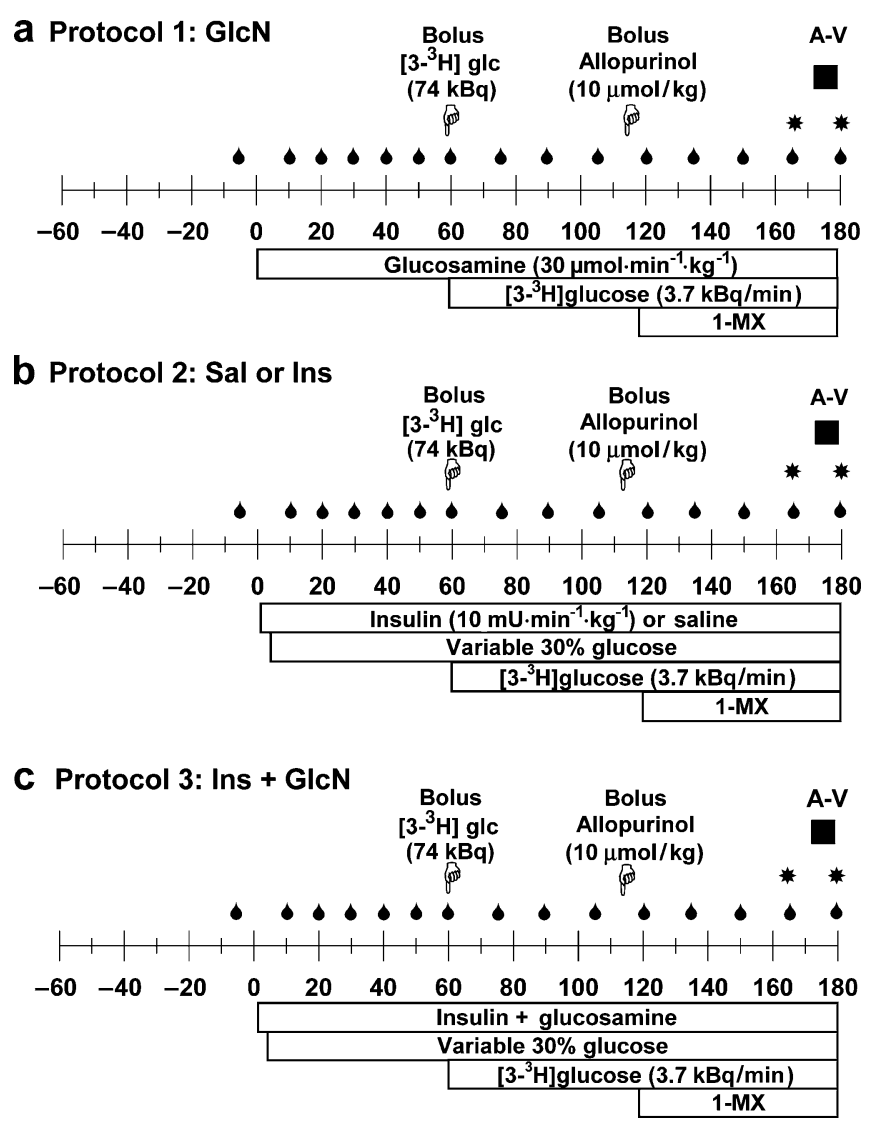

Fig. 1 Protocols 1 (a), 2 (b) and 3 (c) for the in vivo experiments. Venous infusions are indicated by the horizontal bars. Bolus injections are indicated by the finger symbol. Droplet symbols: times at which blood glucose was measured in arterial samples; *arterial samples for the determination of radioactivity; solid square: times at which arterial and venous samples were collected for analysis

from the arterio-venous difference multiplied by the flow. A primed $(74 \mathrm{kBq})$ continuous infusion $\left(3.7 \mathrm{kBq} / \mathrm{min}^{-1}\right)$ of $\left[{ }^{3} \mathrm{H}\right]$ glucose (Amersham Life Science, Castle Hill, NSW, Australia) was administered during the final $2 \mathrm{~h}$. Arterial plasma samples taken at 165 and $180 \mathrm{~min}$ were deproteinated, evaporated to dryness to remove ${ }^{3} \mathrm{H}_{2} \mathrm{O}$, resuspended and $\left[{ }^{3} \mathrm{H}\right]$ glucose radioactivity determined. The rate of appearance $\left(R_{\mathrm{a}}\right)$ and rate of disappearance $\left(R_{\mathrm{d}}\right)$ of glucose were calculated using the isotope dilution equation

$R_{\mathrm{a}}+\mathrm{GIR}=R_{\mathrm{d}}=F / \mathrm{SA}$

where $F$ is the rate of tracer infusion and SA is the specific activity of glucose [22]. SA was calculated from the plasma radioactivity divided by the glucose concentration.

Although the conditions in the glucosamine group are not strictly steady-state, the increase in blood glucose was only minimal over the final hour (approximately 10\%) and therefore it was a reasonable approximation to use the equation for steady state. Assuming the SA also changed by $10 \%$ over the final hour, it was calculated that the error in the $R_{\mathrm{a}}$ and $R_{\mathrm{d}}$ measurements would only be approximately $5 \%$. 
Femoral arterial blood flow and capillary recruitment Femoral arterial blood flow (FBF) was continuously measured from a Transonic flow probe positioned around the femoral artery of one leg. Capillary recruitment was determined by measuring the metabolism of infused 1methylxanthine (1-MX), a substrate targeted for xanthine oxidase, which in the hind leg muscle is located predominantly in capillary endothelium [23]. 1-MX (Sigma Chemical, St Louis, MO, USA) was infused at a constant rate $\left(0.5 \mathrm{mg} \mathrm{kg}^{-1} \mathrm{~min}^{-1}\right.$, Fig. 1) to maintain a steady-state arterial level of approx. $20 \mu \mathrm{mol} / 1$. As noted previously $[12,21]$ this was achieved by partly inhibiting the activity of xanthine oxidase with allopurinol [24] $(10 \mu \mathrm{mol} / \mathrm{kg})$, administered as a bolus dose 5 min prior to commencing the 1-MX infusion (Fig. 1). This not only allowed constant arterial concentrations of 1-MX to be maintained throughout the experiment, but also lowered the $K_{\mathrm{m}}$ of the enzyme sufficiently for 20 $\mu \mathrm{mol} / \mathrm{l} 1-\mathrm{MX}$ to be well above saturation (Harper MJ, Rattigan S, Clark MG, unpublished observations).

Plasma $(100 \mu \mathrm{l})$ from arterial and leg venous blood samples taken at the end of the experiment was mixed with $20 \mu \mathrm{l}$ of $2 \mathrm{~mol} / \mathrm{l}$ perchloric acid and centrifuged for $10 \mathrm{~min}$. The supernatant was used to determine 1-MX, allopurinol and oxypurinol concentrations by reverse-phase HPLC as previously described [21]. Capillary recruitment, expressed as 1-MX metabolism was calculated from arterio-venous plasma 1-MX concentration difference and multiplied by FBF. The concentration in plasma was corrected for the volume accessible to 1-MX, determined from plasma concentrations obtained after additions of standard 1-MX to whole rat blood to be $87.1 \%$. The rate of 1-MX metabolism across the hind leg (expressed as $\mathrm{nmol} / \mathrm{min}$ ) reflects conversion by capillary endothelial xanthine oxidase to the sole product, 1-methyl urate [25].

Xanthine oxidase activity This was assayed in muscles frozen in liquid nitrogen at the end of the experiment and stored at $-70^{\circ} \mathrm{C}$ until assayed. Muscle was powdered under liquid $\mathrm{N}_{2}$ and $400 \mathrm{mg}$ was homogenised in $2 \mathrm{ml}$ of buffer (50 $\mathrm{mmol} / 1 \mathrm{Na}_{2} \mathrm{HPO}_{4}, 0.1 \mathrm{mmol} / 1 \mathrm{Na}_{2} \mathrm{EDTA}, 4 \mathrm{mmol} / \mathrm{l} \mathrm{DTT}$, $0.5 \mathrm{mg} / \mathrm{ml}$ trypsin inhibitor, $\mathrm{pH}$ 7.4) and then centrifuged for $30 \mathrm{~min}$ at $50,000 \times \mathrm{g}$. The supernatant was passed through a PD-10 desalting column (Amersham Pharmacia Biotech, Uppsala, Sweden) and the protein fractions collected. A sample of the protein fraction $(100 \mu \mathrm{l})$ was added to the assay mix $(0.9 \mathrm{ml})$, which consisted of buffer (as above) and $100 \mu \mathrm{mol} / \mathrm{l}$ xanthine, the substrate for xanthine oxidase, and was incubated at $37^{\circ} \mathrm{C}$ for $60 \mathrm{~min}$. The reaction was stopped by adding $250 \mu \mathrm{l}$ of assay mix to $50 \mu \mathrm{l}$ of 2 $\mathrm{mol} / \mathrm{l}$ perchloric acid. The amount of uric acid formed from xanthine was determined by HPLC using a Luna 5 $\mu \mathrm{m}$ C8 column (Phenomenex, Torrance, CA, USA) with isocratic separation in $50 \mathrm{mmol} / 1 \mathrm{NH}_{4} \mathrm{H}_{2} \mathrm{PO}_{4} \mathrm{pH} 3.5$ buffer at $1.2 \mathrm{ml} / \mathrm{min}$. Protein amounts were determined using a Bradford protein assay kit (Bio-Rad Laboratories, Hercules, CA, USA). Activity was expressed as pmol $\mathrm{min}^{-1} \mathrm{mg}^{-1}$ protein.
Plasma glucosamine Plasma levels of glucosamine in vivo were determined in arterial samples taken at $180 \mathrm{~min}$ [26]. Protein free plasma samples were neutralised and reacted at room temperature for $20 \mathrm{~min}$ with a mixture of methanol : triethylamine : phenylisothiocyanate (70:10:5). After quenching the reaction with $1.5 \%$ acetic acid, two chloroform extractions were performed. The aqueous phase, along with similarly treated standards, was run on HPLC to determine the content of glucosamine [26].

Data analysis All data are expressed as means \pm SE. Mean FBF, mean heart rate and mean arterial BP were calculated from 5-s subsamples of the data, representing approximately 500 flow and pressure measurements every $15 \mathrm{~min}$. Vascular resistance in the hind limb was calculated as mean arterial $\mathrm{BP}$ in $\mathrm{mmHg}$ divided by $\mathrm{FBF}$ in $\mathrm{ml} / \mathrm{min}$ and expressed as resistance units (RUs). HGU was calculated from A-V glucose difference and multiplied by FBF and expressed as $\mu \mathrm{mol} / \mathrm{min}$. In order to ascertain differences between treatment groups at the end of the experiment (180 min), one-way analysis of variance was used. When a significant difference $(p<0.05)$ was found, Dunnett's test was used to determine which groups were significantly different from $\mathrm{N}$-glucosamine $(\mathrm{GlcN})$ control. Pairwise comparisons were made using the Student-Newman-Keuls Method. All tests were performed using the SigmaStat statistical program (Jandel Software, San Raphael, CA, USA).

\section{Results}

Plasma glucosamine, glucose and insulin Plasma glucosamine was undetectable in basal samples from all rats and also at the completion of the insulin infusion. The infusion rate of glucosamine of $6.48 \mathrm{mg} \mathrm{kg}^{-1} \mathrm{~min}^{-1}$ was based on that used by others [8] and raised plasma glucosamine to $1.9 \pm 0.1 \mathrm{mmol} / 1$ and $2.0 \pm 0.2 \mathrm{mmol} / 1$ in the glucosamine and the insulin+glucosamine groups, respectively. Preliminary studies using the isolated perfused rat hind limb had shown that $2 \mathrm{mmol} / \mathrm{l}$ glucosamine significantly increased metabolites of the glucosamine pathway in muscle (UDP$N$-acetylglucosamine increased from $66.5 \pm 5.5[n=6$, saline $]$ to $143.2 \pm 4.3 \mathrm{nmol} / \mathrm{g}$ wet wt $[n=6, \mathrm{GlcN}])$. Blood glucose was not significantly different between the three groups (Fig. 1) or saline at the beginning of the experiment. Glucosamine infusion caused a significant rise in blood glucose levels (Fig. 2); however, in the insulin and insulin+ glucosamine groups blood glucose levels were clamped to the basal level.

Basal plasma insulin levels were not significantly different between the three groups (glucosamine $279 \pm 33 \mathrm{pmol} / \mathrm{l}$; insulin $184 \pm 21 \mathrm{pmol} / \mathrm{l}$; insulin+glucosamine $194 \pm 44 \mathrm{pmol} / \mathrm{l})$. In both the insulin and insulin+glucosamine groups, insulin levels were significantly raised to $1,724 \pm 133$ and $1,715 \pm 252 \mathrm{pmol} / \mathrm{l}$, respectively. Despite the rise in blood glucose levels in the glucosamine group, there was no 
Fig. 2 Blood glucose (a), glucose infusion rate $(\mathbf{b})$, glucose appearance rate $\left(R_{\mathrm{a}}\right),(\mathbf{c})$ and glucose disposal rate $\left(R_{\mathrm{d}}\right)$, (d) for anaesthetised rats infused with saline (Sal, open circles), GlcN (light-shaded circles), insulin (Ins, black squares) or GlcN+Ins (dark-shaded squares). Data for $R_{\mathrm{a}}$ and $R_{\mathrm{d}}$ were collected 180 min after commencement of infusions (see Fig. 1). Values are means \pm SE for $n=8-10$ in each group. ${ }^{*} p<0.05$ difference from Sal; ${ }^{\#} p<0.05$ difference from Ins
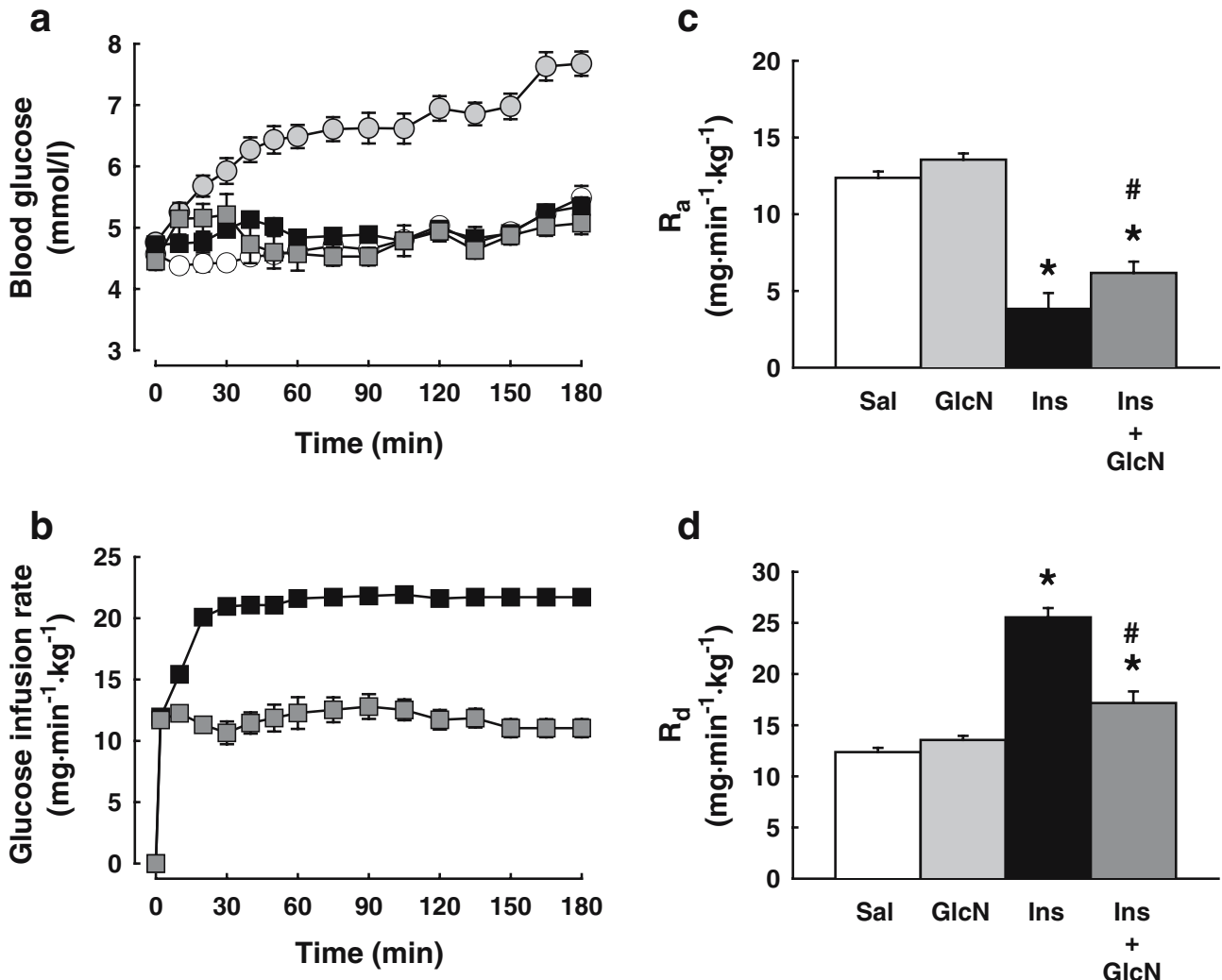

significant increase in insulin levels throughout the experiment $(358 \pm 72 \mathrm{pmol} / \mathrm{l})$. This is consistent with the findings that glucosamine impairs glucose-induced insulin secretion in rats $[6,27]$.

Glucose metabolism The glucose infusion rate in the insulin+glucosamine group was significantly lower than for insulin alone (Fig. 2). The glucose infusion rate and the specific activity of $\left[{ }^{3} \mathrm{H}\right]$ glucose at steady state $(180 \mathrm{~min})$ were used to determine glucose appearance $\left(R_{\mathrm{a}}\right)$ and glucose disposal $\left(R_{\mathrm{d}}\right)$. The specific activity values $(\mathrm{kBq} / \mathrm{mg})$ were $1.09 \pm 0.05$ (saline), $0.95 \pm 0.03$ (glucosamine), $0.53 \pm 0.03$ (insulin) and $0.81 \pm 0.04$ (insulin+glucosamine). Glucosamine alone had no effect on either $R_{\mathrm{a}}$ or $R_{\mathrm{d}}$ relative to saline control (Fig. 2), but blocked both the insulin-mediated decrease in $R_{\mathrm{a}}$ and the increase in $R_{\mathrm{d}}$. Since the rats were not fasted, the values of $R_{\mathrm{a}}$ may be slightly overestimated as a result of the absorption of glucose from the gut, thereby explaining why glucose appearance largely of hepatic origin was not more fully suppressed by $10 \mathrm{mU} \mathrm{kg}^{-1} \mathrm{~min}^{-1}$ insulin. Specifically with regard to glucose metabolism across the hind leg, glucose extraction was increased in the insulin and insulin+glucosamine groups relative to saline, and glucosamine alone significantly decreased glucose extraction relative to saline (Fig. 3). When blood flow was taken into account, the increase in hind leg glucose uptake by insulin was significantly reduced in the insulin + glucosamine group (Fig. 3). Glucosamine alone appeared to give rise to a lower glucose uptake than saline alone, but this was not significant.
Haemodynamic measurements Figure 4 shows that basal mean arterial pressure was similar in all groups, but by the end of the experiment both the insulin and insulin+ glucosamine groups $(117 \pm 3 \mathrm{mmHg})$ showed significantly higher pressures than the glucosamine-alone group $(106 \pm 3 \mathrm{mmHg})$. None of the infusions affected heart rate (Fig. 4). At the end of the experiment, FBF was significantly higher in the insulin group than in the saline or glucosamine-alone groups; however, in the insulin+glucosamine group, insulin did not significantly raise the flow above that of the glucosamine-alone group (Fig. 4). There was a trend for insulin to reduce femoral vascular resistance and for this effect to be blocked in the insulin+ glucosamine group, although this did not reach statistical significance (Fig. 4).

1-MX Metabolism There were no differences in the arterial plasma levels of 1-MX between the four groups; these were $19.3 \pm 1.0,22.5 \pm 1.9,23.7 \pm 1.5$ and $23.5 \pm 2.5 \mu \mathrm{mol} / 1$ for saline, glucosamine, insulin and insulin + glucosamine, respectively. Arterial plasma levels of oxypurinol also did not differ and these were $4.5 \pm 0.3,4.7 \pm 0.2,5.6 \pm 0.7$ and $5.2 \pm 0.3 \mu \mathrm{mol} / 1$ for saline, glucosamine, insulin and insulin+glucosamine, respectively. The 1-MX disappearance was significantly increased by insulin relative to either saline or glucosamine alone (Fig. 5) and in the insulin+glucosamine group 1-MX metabolism was significantly different from insulin alone, indicating that insulin's ability to recruit capillaries was totally blocked by glucosamine (Table 1). 

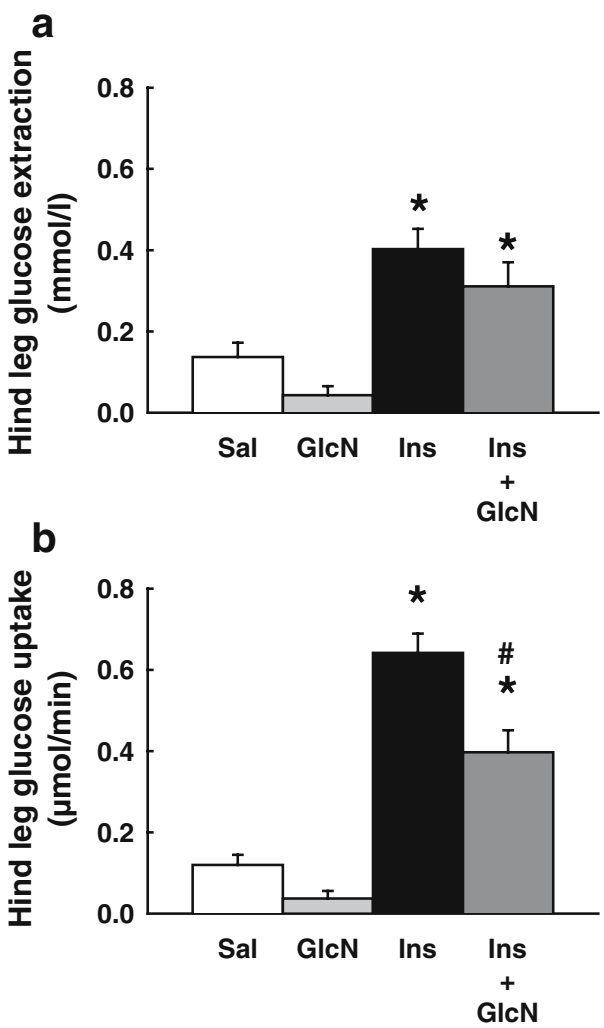

Fig. 3 Glucose extraction (a) and glucose uptake (b) measured across the hind limb of anaesthetised rats infused with saline ( $\mathrm{Sal}$ ), GlcN, Ins, or GlcN+Ins. Data were collected $180 \mathrm{~min}$ after the commencements of the infusions as shown in Fig. 1. Values are means \pm SE for $n=8-9$ in each group. ${ }^{*} p<0.05$ for difference from $\mathrm{Sal} ;{ }^{\#} p<0.05$ for difference from Ins

Xanthine oxidase activity Metabolism of 1-MX by xanthine oxidase of the hind limb muscle vasculature, which is measured under saturating conditions of 1-MX, has been shown to reflect changes in nutritive flow $[25,28]$. However, because conditions are saturating, a change in the level of xanthine oxidase activity could also influence the rate of metabolism of 1-MX. Accordingly, xanthine oxidase activity was determined for the critical experiments. We found no significant difference in the xanthine oxidase activity measured in tibialis muscle extracts at the completion of the experiment (glucosamine $61 \pm 9$; insulin $58 \pm 7$; insulin+glucosamine $62 \pm 14 \mathrm{pmol} \mathrm{min}^{-1} \mathrm{mg}^{-1}$ protein). Therefore it is likely that differences in 1-MX metabolism are indicative of changes in capillary surface area, rather than an effect on constitutive xanthine oxidase activity.

\section{Discussion}

In agreement with others, our in vivo experiments showed that glucosamine markedly reduced insulin-stimulated glucose disposal, hind limb glucose uptake and also impaired insulin's ability to suppress glucose appearance, presumably as hepatic glucose output [6-8, 29]. The important findng in this study was that glucosamine infusion markedly impaired insulin-mediated increases in total flow and capillary recruitment. An impairment of insulin-mediated increases in total flow has been observed by others [20] when total flow to individual muscles in vivo was assessed using microspheres at the completion of the experiment. However, this is the first study to demonstrate that the microvascular response to insulin in terms of capillary recruitment is also blocked by glucosamine.

To assess changes in capillary recruitment, we used the 1-MX method, which in previous studies [21] has proved to be appropriate for assessing acute changes in capillary recruitment, providing steady-state conditions apply for both substrate and enzyme. For the enzyme, total xanthine oxidase activity was not altered by acutely administered
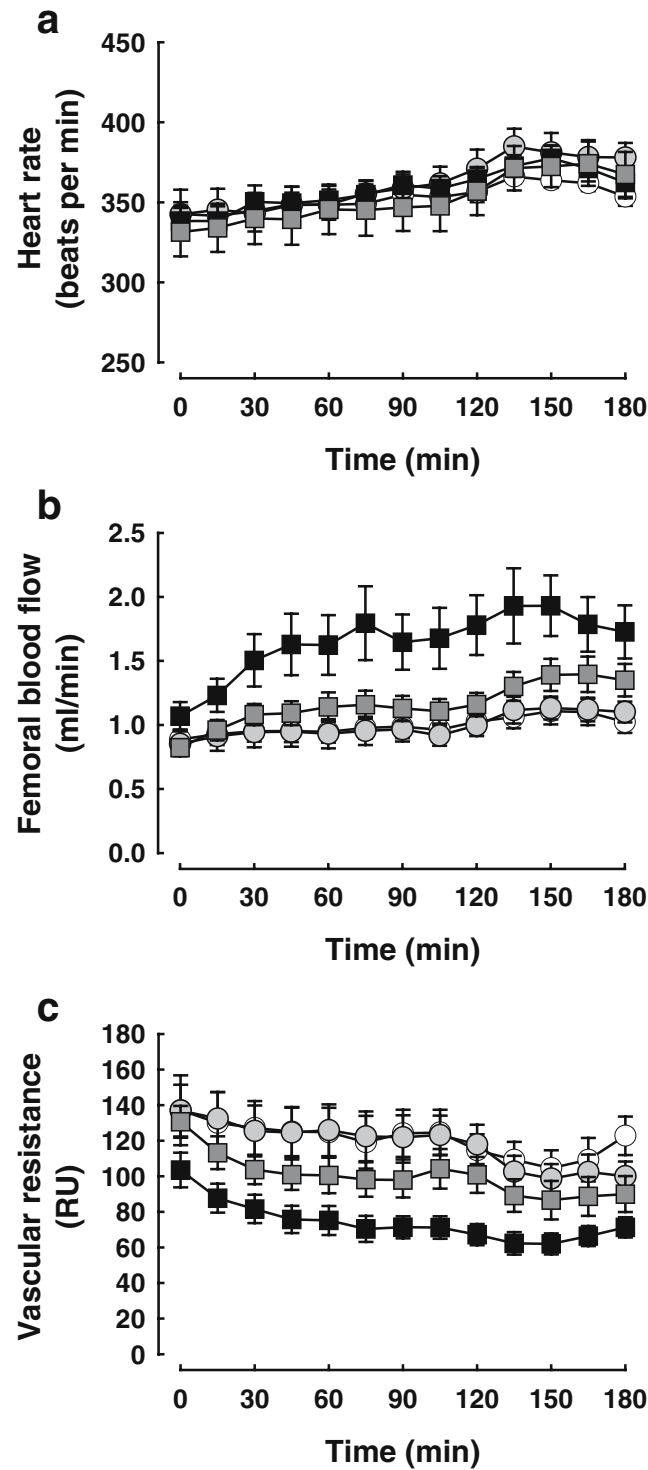

Fig. 4 Heart rate (a), femoral arterial blood flow (b) and vascular resistance (c) of anaesthetised rats infused with saline (open circles), GlcN (light-shaded circles), insulin (black squares), or GlcN+insulin (dark-shaded squares). Values are means \pm SE for $n=8-9$ in each group 
Table 1 Arterial and venous plasma 1-MX concentrations, femoral arterial flow rate and calculated hind limb 1-MX metabolism for anaesthetised rats infused with saline, $N$-glucosamine, insulin or both $N$-glucosamine and insulin

\begin{tabular}{|c|c|c|c|c|}
\hline & $\begin{array}{l}\text { Arterial 1-MX } \\
(\mu \mathrm{mol} / 1)\end{array}$ & $\begin{array}{l}\text { Venous } 1-\mathrm{MX} \\
(\mu \mathrm{mol} / \mathrm{l})\end{array}$ & 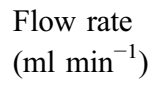 & $\begin{array}{l}\text { 1-MX metabolism } \\
\left(\mathrm{nmol} \mathrm{min}{ }^{-1}\right)\end{array}$ \\
\hline Saline & $19.3 \pm 1.0$ & $13.4 \pm 0.7$ & $1.02 \pm 0.08$ & $4.9 \pm 0.3$ \\
\hline$N$-glucosamine & $22.5 \pm 1.8$ & $15.5 \pm 0.9$ & $1.10 \pm 0.08$ & $6.5 \pm 1.0$ \\
\hline Insulin & $23.6 \pm 1.6$ & $15.9 \pm 1.0$ & $1.73 \pm 0.21$ & $10.8 \pm 1.2 *$ \\
\hline$N$-glucosamine & $23.5 \pm 2.4$ & $17.3 \pm 1.2$ & $1.35 \pm 0.13$ & $7.4 \pm 1.3^{\#}$ \\
\hline
\end{tabular}

Data were collected 180 min after the commencement of the infusions as shown in Fig. 1

Values are means \pm SE for $n=8$ in each group

${ }^{*} p<0.05$ difference from saline; ${ }^{*} p<0.05$ difference from insulin

glucosamine. With regard to the substrate, we established that the plasma 1-MX concentration is at steady state with the procedure used in the present study, provided that partial inhibition of whole-body, in particular renal 1-MX metabolism, is reduced. Most importantly we had previously directly compared the 1-MX method with an ultrasound/ microbubbles imaging method [17] and the agreement between the two methods was excellent. Also a third method involving scanning or fixed probe LDF, has shown an insulin-mediated capillary recruitment in muscle in vivo [30].

Despite the loss of insulin-mediated haemodynamic effects, the interaction between insulin and glucosamine is likely to be complex. In particular, the temporal relationship between insulin signalling and impairment by glucosamine is hard to predict and may depend on duration of exposure and when each is added relative to the other. For the present in vivo experiments our objective was to test whether the early microvascular effect of insulin [18] was impaired by glucosamine. Our approach was to add glucosamine and insulin simultaneously in the belief that the initial site of interaction was the endothelial or vascular smooth muscle cells, from where bulk flow and capillary recruitment are likely to be controlled. The outcome was that each of the insulin-mediated haemodynamic effects was blocked and overall insulin-mediated glucose uptake by the hind leg reduced by approximately $50 \%$.

The present findings may explain part of the basis of the insulin resistance that develops in vivo where this would now appear to involve a major impairment of the vasculature. Thus, although the exact mechanism of glucosamineinduced insulin resistance is not established, it has been proposed that either insulin signalling is inhibited and/or the translocation of GLUT4 is impaired. While there is some evidence for the former, there are some discrepancies in the findings. One research group [31] reported that insulinstimulated IRS-1 tyrosine phosphorylation was reduced by glucosamine, whereas another [32] found this was preserved in glucosamine-treated rats. When measured 1 min after a bolus injection of insulin, PI3 kinase (PI3K) activity associated with IRS-1 was decreased by glucosamine infusion, on the other hand, when the activity was measured following $2 \mathrm{~h}$ of insulin infusion, no effect of glucosamine was observed [32]. Also, it was found that glucosamine reduced insulin- stimulated IRS-1-associated PI3K activity [31]; however, these measurements were taken at the end of a $6 \mathrm{~h}$ infusion of insulin and glucosamine. Interestingly, when this was measured after only $2 \mathrm{~h}$ infusion, glucosamine had no effect [31]. In contrast to this, impaired insulin stimulation of PI3K activity was seen as early as 30 min after glucosamine infusion [33]. Despite this, there was no significant reduction in glucose uptake until $110 \mathrm{~min}$ of glucosamine infusion. Insulinstimulated Akt/PKB activity was unaltered by glucosamine [32]. Although those studies were performed on skeletal muscle, similar alterations in insulin signalling may also be effected in vascular tissue, leading to the impaired total flow and capillary recruitment seen here.

Also, recent studies [34] have demonstrated that GFAT is present in endothelial cells, and that glucosamine inhibits NO production in cultured endothelial cells exposed to glucosamine for $24 \mathrm{~h}$ [35]. Rather than having a direct effect on NOS activity, this is a consequence of the inhibition of the pentose cycle and subsequent decreased levels of the essential cofactor for NOS, NADPH [35]. Similarly, other studies have shown that endothelium-dependent vasodilation was impaired in thoracic aorta rings from rats infused with glucosamine and that this was a result of the inhibition of NOS by glucosamine [19]. Since both the insulin-mediated increases in total flow $[15,36]$ and capillary recruitment [16] have been suggested to be NOSdependent, this could be the mechanism for the glucosamine-mediated inhibition of capillary recruitment and total flow. The effects of glucosamine on gene expression in endothelial cells [37] should also be considered, if longer-term exposure occurs.

It is important to note that failure of the vascular endothelial insulin receptor knockout (VENIRKO) mouse to show impaired insulin-stimulated glucose disposal [38] weakens the proposal that endothelial NO is involved in the vascular action of insulin, by which insulin increases access for glucose and itself, thereby contributing to glucose uptake by muscle. Evidence from a number of laboratories indicates that limb blood flow is controlled by insulin acting via a NO-dependent mechanism presumed to be initiated via vascular endothelial cells $[15,36,39]$. However, the role of limb blood flow in insulin-mediated glucose uptake is at best controversial [40]. Thus, in this respect the VENIRKO mouse helps to resolve the controversy. In 
contrast, there is growing evidence that insulin-mediated capillary recruitment may play a key role in muscle glucose uptake, particularly in animal models [18] and is impaired in animal models of muscle insulin resistance [12-14, 41] and in obese humans [42, 43]. Capillary recruitment is controlled independently of limb blood flow [17, 18, 21] and occurs in response to locally administered physiological insulin in human forearm in association with glucose uptake [44]. In the absence of an endothelial involvement, insulin may act directly on vascular smooth muscle cells of the terminal arterioles to mediate capillary recruitment. Clearly, further studies are required to address this issue. In addition it will be important to test whether the VENIRKO mouse responds to insulin in terms either of capillary recruitment and/or of limb blood flow.

Alternatively, the haemodynamic effects of insulin may result from increased glucose uptake and subsequent release of a metabolic vasodilator, in which case the blunted haemodynamic actions may be secondary to the impairment of metabolism by glucosamine. In this regard it has been suggested that the insulin resistance induced by glucosamine is caused by an impaired translocation of GLUT4 to the plasma membrane [45]. This has been proposed to result from glycosylation of proteins involved in the translocation and docking of GLUT4 to the plasma membrane [45]. Indeed the incorporation of labelled glucosamine into GLUT4containing vesicles was increased by glucosamine infusion [46]. The finding that glucosamine inhibited the translocation of both an insulin-sensitive and an insulin-insensitive pool of GLUT4 [45] implies that glucosamine can act directly on GLUT 4 translocation. This is further supported by studies demonstrating that exercise-stimulated glucose uptake is also impaired by glucosamine [47]. However, there is now indirect evidence making it unlikely that insulinmediated capillary recruitment is regulated by metabolite(s) from muscle. Thus insulin-mediated capillary recruitment, measured by contrast-enhanced ultrasound, is an early event in insulin action in vivo preceding the stimulation of glucose uptake [18]. We have also shown, using both 1-MX metabolism and contrast-enhanced ultrasound, that capillary recruitment occurs at insulin concentrations that do not alter muscle glucose uptake [17].

If the impaired haemodynamic changes observed here are a major outcome of and possibly contributor to, the insulin resistance induced by glucosamine, then impaired haemodynamics may also play a role in glucose toxicity. In general terms, a number of studies indicate that increased flux through the hexosamine biosynthesis pathway may be involved in the insulin resistance induced by hyperglycaemia. For example, GFAT activity was found to be higher in muscle from type 2 diabetic subjects [48]. This may be a result of hyperglycaemia and/or hyperinsulinaemia as each of these has been shown to upregulate GFAT activity [49]. Moreover, in rats the insulin resistance induced by chronic hyperglycaemia and glucosamine was not additive, suggesting a shared mechanism [7]. However, more recent studies suggest that there are differences in the mecha- nisms, since troglitazone treatment prevents the insulin resistance associated with hyperglycaemia, but not that associated with glucosamine [29]. In muscle the level of UDP-GlcN was positively correlated with the decrease in glucose infusion rate [46]. Interestingly, in humans, glucosamine infusion impairs insulin-mediated glucose utilisation under hyperglycaemia, but not at euglycaemia $[50]$ as it does in rats $[6,7]$. Taken together, it seems that glucosamine does model high-glucose-induced insulin resistance in muscle and it would be interesting to investigate whether high glucose also inhibits insulin-mediated capillary recruitment.

It is important to note that the present in vivo findings were obtained from anaesthetised animals where neuronal reflexes may be suppressed and thus distort the outcomes and highlight a vascular component of insulin resistance that might be less pronounced in conscious animals. However, in the present studies, the heart rate and blood pressure were normal and other recent studies have shown that insulin-mediated capillary recruitment occurred early, relative to muscle glucose uptake [18] and at physiological doses of insulin [17], indicating that a desensitising effect of the anaesthetic is unlikely. Moreover, studies in human forearm, where the subjects were instructed to remain still, have shown insulin-mediated capillary recruitment, again at physiological insulin levels [44].

Further studies are required to confirm that the present findings are relevant to human subjects, where, so far, glucosamine has not been seen to affect insulin-mediated glucose uptake [51]. This may reflect an involvement by liver, a species difference in the handling of glucosamine, since similar plasma levels of GlcN did induce insulin resistance in the rat [31]. Or it may simply be the result of not achieving sufficiently high levels of intracellular metabolites of the glucosamine pathway in muscle cells. Thus, short-term infusion of glucosamine into the forearm of healthy human subjects achieved 0.42 and 0.81 $\mathrm{mmol} / \mathrm{l}$, but these were without effect [51]. In the present study, plasma levels were approximately $2 \mathrm{mmol} / 1$ and there was evidence that, at this level, significant metabolism had occurred.

In summary, glucosamine administered acutely in vivo induced a state of muscle insulin resistance that was associated with markedly impaired haemodynamics where, in the presence of glucosamine, insulin did not significantly increase total flow or capillary recruitment. We propose that glucosamine inhibits insulin signalling in as yet unidentified site(s), thereby blocking the increases in total flow and capillary recruitment. In so doing, impaired access for insulin and glucose may ensue, contributing to insulin resistance in a similar way to previous experimental situations, where capillary recruitment by insulin was blocked [12-14].

Acknowledgements This work was supported, in part, by the National Health and Medical Research Council, Australian Research Council and the Heart Foundation of Australia. S. Rattigan is a Heart Foundation Career Fellow. 


\section{References}

1. Rossetti L, Giaccari A, DeFronzo RA (1990) Glucose toxicity. Diabetes Care 13:610-630

2. Garvey WT, Olefsky JM, Matthaei S, Marshall S (1987) Glucose and insulin co-regulate the glucose transport system in primary cultured adipocytes. A new mechanism of insulin resistance. J Biol Chem 262:189-197

3. Traxinger RR, Marshall S (1989) Role of amino acids in modulating glucose-induced desensitization of the glucose transport system. J Biol Chem 264:20910-20916

4. Marshall S, Bacote V, Traxinger RR (1991) Discovery of a metabolic pathway mediating glucose-induced desensitization of the glucose transport system. Role of hexosamine biosynthesis in the induction of insulin resistance. J Biol Chem 266: 4706-4712

5. Hebert LF Jr, Daniels MC, Zhou J et al (1996) Overexpression of glutamine: fructose-6-phosphate amidotransferase in transgenic mice leads to insulin resistance. J Clin Invest 98:930-936

6. Giaccari A, Morviducci L, Zorretta D et al (1995) In vivo effects of glucosamine on insulin secretion and insulin sensitivity in the rat: possible relevance to the maladaptive responses to chronic hyperglycaemia. Diabetologia 38:518-524

7. Rossetti L, Hawkins M, Chen W, Gindi J, Barzilai N (1995) In vivo glucosamine infusion induces insulin resistance in normoglycemic but not in hyperglycemic conscious rats. J Clin Invest 96:132-140

8. Hawkins M, Barzilai N, Chen W et al (1996) Increased hexosamine availability similarly impairs the action of insulin and IGF-1 on glucose disposal. Diabetes 45:1734-1743

9. Virkamaki A, Daniels MC, Hamalainen S, Utriainen T, McClain D, Yki-Jarvinen H (1997) Activation of the hexosamine pathway by glucosamine in vivo induces insulin resistance in multiple insulin sensitive tissues. Endocrinology 138:2501-2507

10. Robinson KA, Sens DA, Buse MG (1993) Pre-exposure to glucosamine induces insulin resistance of glucose transport and glycogen synthesis in isolated rat skeletal muscles. Study of mechanisms in muscle and in rat-1 fibroblasts overexpressing the human insulin receptor. Diabetes 42:1333-1346

11. Furnsinn C, Sanderson AL, Radda GK, Leighton B (1995) Effects of glucosamine on insulin-stimulated glucose metabolism in rat soleus muscle. Int J Biochem Cell Biol 27:805-814

12. Rattigan S, Clark MG, Barrett EJ (1999) Acute vasoconstriction-induced insulin resistance in rat muscle in vivo. Diabetes 48:564-569

13. Youd JM, Rattigan S, Clark MG (2000) Acute impairment of insulin-mediated capillary recruitment and glucose uptake in rat skeletal muscle in vivo by TNF $\alpha$. Diabetes 49:1904-1909

14. Clerk LH, Rattigan S, Clark MG (2002) Lipid infusion impairs physiological insulin-mediated capillary recruitment and muscle glucose uptake in vivo. Diabetes 51:1138-1145

15. Steinberg HO, Brechtel G, Johnson A, Fineberg N, Baron AD (1994) Insulin-mediated skeletal muscle vasodilation is nitric oxide dependent. A novel action of insulin to increase nitric oxide release. J Clin Investig 94:1172-1179

16. Vincent MA, Barrett EJ, Lindner JR, Clark MG, Rattigan S (2003) Inhibiting NOS blocks microvascular recruitment and blunts glucose uptake in response to insulin. Am J Physiol 285: E123-E129

17. Zhang L, Vincent MA, Richards SM et al (2004) Insulin sensitivity of muscle capillary recruitment in vivo. Diabetes 53:447-453

18. Vincent MA, Clerk LH, Lindner JR et al (2004) Microvascular recruitment is an early insulin effect that regulates skeletal muscle glucose uptake in vivo. Diabetes 53:1418-1423

19. Shankar RR, Wu Y-G, Baron AD, Shankar SS (2001) Glucosamine impairs endothelial function by inhibiting nitric oxide synthase. Diabetes 50:A165

20. Holmang A, Nilsson C, Niklasson M, Larsson BM, Lonroth P (1999) Induction of insulin resistance by glucosamine reduces blood flow but not interstitial levels of either glucose or insulin. Diabetes 48:106-111
21. Rattigan S, Clark MG, Barrett EJ (1997) Hemodynamic actions of insulin in rat skeletal muscle: evidence for capillary recruitment. Diabetes 46:1381-1388

22. Burnol AF, Leturque A, Ferre P, Girard J (1983) A method for quantifying insulin sensitivity in vivo in the anesthetized rat: the euglycemic insulin clamp technique coupled with isotopic measurement of glucose turnover. Reprod Nutr Dev 23:429-435

23. Jarasch ED, Bruder G, Heid HW (1986) Significance of xanthine oxidase in capillary endothelial cells. Acta Physiol Scand Suppl 548:39-46

24. Emmerson BT, Gordon RB, Cross M, Thomson DB (1987) Plasma oxipurinol concentrations during allopurinol therapy. Br J Rheumatol 26:445-449

25. Rattigan S, Appleby GJ, Miller KA et al (1997) Serotonin inhibition of 1-methylxanthine metabolism parallels its vasoconstrictor activity and inhibition of oxygen uptake in perfused rat hindlimb. Acta Physiol Scand 161:161-169

26. Anumula KR, Taylor PB (1991) Quantitative determination of phenyl isothiocyanate-derivatized amino sugars and amino sugar alcohols by high-performance liquid chromatography. Anal Biochem 197:113-120

27. Balkan B, Dunning BE (1994) Glucosamine inhibits glucokinase in vitro and produces a glucose-specific impairment of in vivo insulin secretion in rats. Diabetes 43:1173-1179

28. Youd JM, Newman JM, Clark MG et al (1999) Increased metabolism of infused 1-methylxanthine by working muscle. Acta Physiol Scand 166:301-308

29. Miles PD, Higo K, Romeo OM, Lee MK, Rafaat K, Olefsky JM (1998) Troglitazone prevents hyperglycemia-induced but not glucosamine-induced insulin resistance. Diabetes 47:395-400

30. Clark ADH, Barrett EJ, Rattigan S, Wallis MG, Clark MG (2001) Insulin stimulates laser Doppler signal by rat muscle in vivo consistent with nutritive flow recruitment. Clin Sci 100:283-290

31. Patti ME, Virkamaki A, Landaker EJ, Kahn CR, Yki-Jarvinen $H$ (1999) Activation of the hexosamine pathway by glucosamine in vivo induces insulin resistance of early postreceptor insulin signalling events in skeletal muscle. Diabetes 48:15621571

32. Kim YB, Zhu JS, Zierath JR, Shen HQ, Baron AD, Kahn BB (1999) Glucosamine infusion in rats rapidly impairs insulin stimulation of phosphoinositide 3-kinase but does not alter activation of Akt/protein kinase B in skeletal muscle. Diabetes 48:310-320

33. Hawkins M, Hu M, Yu J et al (1999) Discordant effects of glucosamine on insulin-stimulated glucose metabolism and phosphatidylinositol 3-kinase activity. J Biol Chem 274:31312-31319

34. Wu G, Haynes TE, Yan W, Meininger CJ (2001) Presence of glutamine:fructose-6-phosphate amidotransferase for glucosamine-6-phosphate synthesis in endothelial cells: effects of hyperglycaemia and glutamine. Diabetologia 44:196-202

35. Wu G, Haynes TE, Li H, Yan W, Meininger CJ (2001) Glutamine metabolism to glucosamine is necessary for glutamine inhibition of endothelial nitric oxide synthesis. Biochem J 353: 245-252

36. Scherrer U, Randin D, Vollenweider P, Vollenweider L, Nicod $P$ (1994) Nitric oxide release accounts for insulin's vascular effects in humans. J Clin Invest 94:2511-2515

37. Goldberg HJ, Whiteside CI, Fantus IG (2002) The hexosamine pathway regulates the plasminogen activator inhibitor-1 gene promoter and $\mathrm{Sp} 1$ transcriptional activation through protein kinase C-beta I and-delta. J Biol Chem 277:33833-33841

38. Vicent D, Ilany J, Kondo T et al (2003) The role of endothelial insulin signaling in the regulation of vascular tone and insulin resistance. J Clin Invest 111:1373-1380

39. Petrie JR, Ueda S, Webb DJ, Elliott HL, Connell JM (1996) Endothelial nitric oxide production and insulin sensitivity. A physiological link with implications for pathogenesis of cardiovascular disease. Circulation 93:1331-1333

40. Yki-Jarvinen H, Utriainen T (1998) Insulin-induced vasodilatation: physiology or pharmacology? Diabetologia 41:369-379 
41. Wallis MG, Wheatley CM, Rattigan S, Barrett EJ, Clark ADH, Clark MG (2002) Insulin-mediated hemodynamic changes are impaired in muscle of Zucker obese rats. Diabetes 51:34923498

42. Coggins M, Fasy E, Lindner J, Jahn L, Kaul S, Barrett EJ (2000) Obesity blunts insulin's action to recruit capillaries in human skeletal muscle. Diabetes 49(Suppl 1):A237

43. Sjostrand M, Gudbjornsdottir S, Strindberg L, Lonnroth P (2005) Delayed transcapillary delivery of insulin to muscle interstitial fluid after oral glucose load in obese subjects. Diabetes 54:152157

44. Coggins M, Lindner J, Rattigan S et al (2001) Physiologic hyperinsulinemia enhances human skeletal muscle perfusion by capillary recruitment. Diabetes 50:2682-2690

45. Baron AD, Zhu JS, Zhu JH, Weldon H, Maianu L, Garvey WT (1995) Glucosamine induces insulin resistance in vivo by affecting GLUT 4 translocation in skeletal muscle. Implications for glucose toxicity. J Clin Invest 96:2792-2801

46. Hawkins M, Angelov I, Liu R, Barzilai N, Rossetti L (1997) The tissue concentration of UDP- $N$-acetylglucosamine modulates the stimulatory effect of insulin on skeletal muscle glucose uptake. J Biol Chem 272:4889-4895
47. Miles PD, Higo K, Olefsky JM (2001) Exercise-stimulated glucose turnover in the rat is impaired by glucosamine infusion. Diabetes 50:139-142

48. Yki-Jarvinen H, Daniels MC, Virkamaki A, Makimattila S, DeFronzo RA, McClain D (1996) Increased glutamine:fructose-6-phosphate amidotransferase activity in skeletal muscle of patients with NIDDM. Diabetes 45:302-307

49. Daniels MC, Ciaraldi TP, Nikoulina S, Henry RR, McClain DA (1996) Glutamine:fructose-6-phosphate amidotransferase activity in cultured human skeletal muscle cells: relationship to glucose disposal rate in control and non-insulin-dependent diabetes mellitus subjects and regulation by glucose and insulin. J Clin Invest 97:1235-1241

50. Monauni T, Zenti MG, Cretti A et al (2000) Effects of glucosamine infusion on insulin secretion and insulin action in humans. Diabetes 49:926-935

51. Pouwels MJ, Jacobs JR, Span PN, Lutterman JA, Smits P, Tack CJ (2001) Short-term glucosamine infusion does not affect insulin sensitivity in humans. J Clin Endocrinol Metab 86:2099-2103 